\title{
Algunas consideraciones acerca de los Estados Unidos en la época de los años veinte, 1919-1929
}

\author{
Angela Moyano Pahissa
}

Los de los anos veinte. Los ven como generalmente se ocupan poco de los años veinte. Los ven como superficiales, dominados por políticos huecos y conservadores. Piensan que sólo la música tuvo alguna originalidad e influencia y consideran esa etapa sólo como transición entre el Progresismo y el Nuevo Trato; es la terrible era de la Prohibición, la era de la radio y el automóvil. Para muchos ahí acaban sus aportes. Samuel E. Morrison y Henry C. Commager escribieron: "Pocas veces ha habido una generación que herede tan poco que valga la pena..." A su vez Arthur Schlesinger ha dicho: "los veinte están muy lejos de haber sido una época de rebelión, en verdad fue un periodo muy gris..." Sin embargo, ambos autores tienen varias páginas dedicadas a lo que contribuyó a la cultura: la poesía de Robert Frost y de T.S. Eliot, el teatro de Eugene O'Neill, la historia de Vernon L. Parrington y Allan Nevins. ¿Cómo puede minimizarse a una generación que produjo figuras como Hemingway, Dos Passos, Scott Fitzgerald y John Dewey, además de los arriba citados?

La historia de esa década nos ha dejado mitos que empiezan a esclarecerse desde que, a finales de los años sesenta, se abrieron los archivos tanto del presidente Calvin Coolidge como del presidente Herbert Hoover. Los documentos encontrados cambian la interpretación de la época. Los historiadores que han escrito desde entonces la aprecian como rica y compleja pero ambivalente y contradictoria. Es verdad que hubo superficialidad, gasto excesivo, arbitrariedad, resurgimiento de la xenofobia y miedo de las nuevas ideologias, pero también fue un tiempo de experimentación en las comunicaciones y el transporte, de urbanización y de sufragio femenino. Joan Hoff Wilson es de la opinión que los años entre 1921 y 1933 vieron el desarrollo de muchos de los aspectos modernos de la vida norteamericana en política, economía y política exterior. 'Ellis Hawley que en 1978 publicó The Great War and the Search for a Modern Order 1917-1933, escribe en su prefacio: "La importancia de los años veinte, según he.llegado a ver, radica en sus bases ideológicas e institucionales; en este sentido puede haber constituido el periodo más innovador y con más significado de las dos décadas de entreguerras.",

De todos los estereotipos, quizá el único válido sea el de "nueva era" ya que la década dio inicio a la vida moderna en los Estados Unidos: la rápida evolución de los medios de comunicación y transporte, el paso a una economía definitivamente masiva, la transformación de una nación eminentemente rural en una ur-

Joan H. Wilson. The Twenties, The Critical Issues, Boston, Little, Brown and Company, 1972, p. vii.

2 Ellis W. Hawley, The Great War and the Search for a Modern Order, Nueva York. St. Martin's Press, 1979, p. vi. 
bana, nuevas técnicas de investigación, moralidad cambiante, culto a la eficiencia, rápidos cambios tecnológicos y la emergencia de una cultura de masas a través de la radio y del cine, justifican esa denominación para los años de 1921 a 1929.

La primera guerra mundial empujó a los Estados Unidos hacia esa modernidad. En contraste, el periodo anterior parece haber pertenecido al siglo pasado. "En organización económica, conceptos politicos y valores culturales, la década de 1920 tuvo más en común con los Estados Unidos de los ochenta que con la época industrial de finales del siglo XIX." sido fácil, aun cuando hubo personas con visión para aceptarla, la mayoría quería fincarse en su pasado agrario, descentralizado y aislado, propio de un país de segunda importancia mundial; de ahí que la "nueva era" haya estado marcada por una profunda controversia acerca de hasta qué punto debian prevalecer los modernos valores seculares. A pesar de la ambivalencia de las transformaciones que tenían lugar, esa década fue crucial en el cambio de los viejos valores (ejemplificados por la creencia de la ética protestante de abnegación y trabajo) al consumismo, diversión y autorrealización que son la esencia de los tiempos modernos. ${ }^{4}$

Como en toda época de cambio, hubo grupos que se fanatizaron. De ahí la reaparición de la xenofobia y del $\mathrm{Ku}-\mathrm{Klux}-\mathrm{Klan}$, del miedo al progresismo y del rechazo a la Liga de las Naciones en un esfuerzo por cerrarse al mundo. Parece inconcebible que en una nación constituida por inmigrantes se den frecuentes periodos de rechazo al extranjero. Sin embargo así fue y es. En 1919, justamente después de la guerra, la sociedad norteamericana, asustada por la revolución bolchevique y la formación de la Tercera Internacional, entró al periodo llamado del "miedo rojo" (1919-1921) durante el cual deportaron a cientos de inmigrantes recién llegados. El mismo temor a la "contaminación" socialista impelió al Congreso a promulgar leyes restrictivas de la inmigración, sobre todo de Europa Central y Oriental. A eso se añadió la angustia ante lo que se creyó sobrepoblación de las ciudades. Los congresistas declararon que ni sus escuelas ni su fuerza laboral tenian capacidad para absorber más gente. De ahí la presión ciudadana para limitar la inmigración. A mitad de la década, varios estados habian prohibido a los extranjeros la entrada a las profesiones de medicina, arquitectura, etc. Sobre todo, la gente estaba obsesionada por la idea de que ciertas nacionalidades heredaran características de anarquismo y corrupción. La clave ha sido, y es, que a través de su historia los norteamericanos, por razones económicas y emotivas, reaccionan con temor contra los grupos más grandes de una sola nacionalidad de recién llegados, por considerarlos una amenaza a su forma de vida.

Como siempre, fue una minoría la que se dio cuenta de los cambios, de la importancia de ser una nación urbana, de los efectos de la radio y el automóvil. Esa minoría empujó al pueblo hacia la modernidad; se entiende así la confusión y ambivalencia. El gran problema de la época parece haber sido el cómo adaptarse a los cambios y cómo regularlos. "Sería difícil encontrar otra década en

3 James A. Henretta, et. al., America's History since 1865, Chicago, The Dorsey Press. 1987. p. 708.

${ }^{4}$ Ibid. p. 709. 
la historia norteamericana tan revolucionaria en la velocidad de su desarrollo tecnológico y tan incierta de cómo dirigirlo." 5

Se ha acusado a los años veinte de haber frustrado los ideales liberales existentes antes de la primera guerra mundial. Pocas personas siguieron identificándose como progresistas y menos aún como radicales. Sin embargo, en oposición al mito del triunfo total de la derecha, James Weinstein nos dice que los primeros años de la década fueron de intensa agitación radical. Un buen número de sindicalistas y de agricultores trataron de desarrollar una política mucho más de izquierda que la de los progresistas de antaño y en 1924 "casi lograron organizar un tercer partido verdaderamente radical". Su fracaso se debió a la división y a la incapacidad para formular un solo plan de acción. ${ }^{6}$

Se ha dicho que los jóvenes de la década se rebelaron contra los valores tradicionales, esa famosa "revuelta de los jóvenes" fue simplemente un mito. En realidad el estudiante norteamericano siguió siendo conservador, más interesado en autos, bailes y música que en justicia social, guerra o paz. Su única pasión consistió en querer divertirse a toda costa y en romper los códigos sociales.? Sin embargo, la época propició la lucha por la igualdad femenina al pretender liberar a la mujer de los viejos prejuicios victorianos. Si bien de manera escandalosa, se inició la ruptura de una vieja ética que permitía al sexo masculino tener un código moral laxo y libre, contrario al del sexo opuesto. Fue ese cambio el que otorgó más libertad a la mujer que la Enmienda Diecinueve (1920) que le dio el voto.

William G. Harding, presidente electo en 1921, prometió a su pueblo "el retorno a la normalidad", rechazando los avances del progresismo de la preguerra y el intervencionismo gubernamental. Fue ésa una promesa mítica. Todas las ideas y reformas de la época pasada continuaron aunque algunas sufrieron distorsiones al adaptarlas a nuevas circunstancias. El periodo de la "normalidad" fue todo menos eso; la política interna se alineó en un nuevo partidismo en las áreas urbanas, las costumbres cambiaron, los negros empezaron a responder al llamado de un nacionalismo de raza y la economia del laissez faire fue reemplazada por una ideología de cooperación gubernamental y privada. Fue Robert K. Murray quien en su biografia del presidente Harding lo rescató del fracaso al que le había condenado la historia anterior a los años setenta. Todavía en 1966 Arthur Link escribió: "Harding no fue solamente incompetente sino que deshonró el oficio de Presidente..." En oposición, la historia actual lo presenta-como un político astuto y cuidadoso que logró controlar la depresión económica de la posguerra. ${ }^{9}$

El gran acierto político del presidente Harding consistió en

${ }^{5}$ Barry D. Karl, The Uneasy State, the United States from 1915 to 1945, Chicago, The University of Chicago Press, 1983, p. 52.

"James Weinstein, "Radicalism in the midst of Normalcy", en Joan H. Wilson, op. cit., p. 26-27.

'Paul A. Carter, The Twenties in America, Nueva York, Thomas y Crowell Company, 1968, p. 13.

${ }_{8}$ Arthur Link, The Growth of American Demucracy, an Interpretative History, Boston, Ginn and Company, 1966, p. 543.

${ }^{9}$ David Burner, et. al., An American Portrait, Nueva York, Charles Scribner \& Sons, 1985, p. 606. 
aprovechar una debilidad endémica del carácter norteamericano: la de pedir un presidente "normal" en época de transición. Su antecesor, Woodrow Wilson, era recordado como idealista e intelectual, justo el tipo de autoridad temida por el gran público norteamericano. Después de la guerra, la gran mayoria deseaba con nostalgia el regreso a los días sin huelga, inflación y crítica social. De ahí que en un esfuerzo por detener los nuevos tiempos escogiesen como presidente a un politico astuto que se dio cuenta de su intranquilidad.

En su libro Postwar Years: Normalcy 1918-1923, Frederick Paxon escribe que la popularidad del término "normalidad" reflejó un deseo en la teoría, mas no en la práctica de la vida diaria. ${ }^{10}$ El culto a la nueva eficiencia lo demuestra. Las teorías de Frederick Winslow Tylor acerca del manejo científico de la industria pasaron a ser del dominio público y todo ciudadano que se apreciaba trató de ponerlas en práctica en su casa y en su oficina. El mejor ejemplo de su popularidad fue la novela costumbrista Más barato por docena, donde el jefe de familia manejaba su casa como una fábrica. El presidente Coolidge proclamó: "El hombre que.construye una fábrica construye un templo."

En contraste con los literatos que gritaban en contra del consumismo y la apatía del gran público, los científicos sociales trataron de crear nuevas instituciones útiles para alcanzar las nuevas aspiraciones de eficiencia, consumismo y autorrealización. Ni ellos ni los hombres de negocios de la época anticipaban un retorno a la "normalidad". Los negros, las mujeres, los agricultores y los sindicatos tampoco querian un retroceso, simplemente porque no pensaban perder los logros obtenidos durante la guerra. ${ }^{1}$

En su afán de controlar los cambios, la década resultó ser de intolerancia, la Norteamérica tradicional, sintiéndose atacada, quiso imponer homogeneidad por medio de leyes. Leyes para controlar la inmigración, leyes para restringir el consumo de bebidas alcohólicas, leyes para destruir al incipiente socialismo. El fenómeno aparentemente inexplicable de la Prohibición, achacado a los conservadores y a la vuelta a la derecha, fue en realidad un suceso que afectaba a conservadores y liberales. Tanto unos como otros tuvieron gente "seca" y gente "mojada", como llamaban a los que estaban en contra o en favor de la-venta de licor. No fue, como algunos quieren hacer creer, una batalla entre viejos reaccionarios y jóvenes liberales. En ambos grupos hubo partidarios y enemigos de la Enmienda Dieciocho (que prohibió la fabricación, venta y transportación de bebidas intoxicantes); los segundos por considerar que se trataba de una arbitrariedad en contra de la libertad personal. Se llegó a creer que comprar licor era un acto de desobediencia civil a una ley injusta. ${ }^{12}$

En cuanto a las dos figuras principales de la época, los presidentes Coolidge y Hoover, también han sido estereotipadas; Link les llama "do-nothing presidents". A Coolidge se le conoció durante años como el observador pasivo del proceso histórico de la década, como un hombre de pocos sentimientos y muy reservado.

${ }_{10}$ Frederick Paxon, Postwar Years: Normalcy 1918-1923, Berkeley, University of California Press, 1948, p. 25.

11 Wilson, op. cit., p. xi.

12 Carter, op. cit., p. 70. 
Tenemos otra visión desde que Howard Quint y Robert Farrell descubrieron en 1963 en una olvidada caja de la biblioteca pública de su pueblo natal las copias de sus conferencias de prensa. Quint y Farrell las publicaron bajo el título de The Talkative President. Coolidge emerge de esos documentos como un político astuto y muy humano, algo totalmente diferente a la caricatura aparecida en las historias de la época. "Coolidge parece haber utilizado las conferencias de prensa como un medio para formar la opinión pública de manera tan consciente como Franklin Delano Roosevelt y John Kennedy utilizaron las suyas." 13

La historiografía es una materia acumulativa que cambia, muchas veces, la imagen histórica de un periodo. Eso fue lo que sucedió a la década de los veinte. Con la apertura de los archivos del presidente Hoover ha cambiado la visión de su periodo. Hasta hace poco, se describía la elección de 1928 como una lucha entre Alfred Smith, gobernador liberal de Nueva York, y el conservador Herbert Hoover, secretario de Comercio del gobierno de Coolidge. Si bien Al Smith era liberal en cuanto a la legislación agrícola, los documentos prueban ahora que tanto su filosofía económica como sus ideas respecto a política interna y externa eran conservadoras. ${ }^{14}$ Nieto de inmigrantes, su catolicismo representaba una ruptura con la tradición. Su postura radical en contra de la prohibición, además, lo hacía parecer como un impugnador de los valores consagrados. De ahí que, a falta de otros epítetos, fuese calificado de liberal o progresista.

Por su parte, Hoover, anglosajón, protestante, descendiente de una familia establecida en el país varias generaciones atrás, parecía representar la tradición para las masas. Se le estereotipó como conservador, se le vio como una figura inmóvil e intransigente, aunque la información reciente lo muestra como el prototipo del empresario organizador y activo de la época, como hombre consciente cuyos programas anticiparon el Nuevo Trato. Admirado desde entonces como gran ingeniero y hombre eficiente, el Partido Republicano lo nominó candidato a la presidencia presentándolo como "una de las grandes epopeyas de los logros modernos. Descendiente de siete generaciones nacidas en el país, su carrera es un ejemplo vivo de las alturas a las que el americanismo puro puede llegar". "Ellis Hawley describe al presidente Hoover como una figura de transición y Noggle como un hombre que buscó la producción eficiente, la innovación tecnológica y la eliminación del desperdicio, mientras que al mismo tiempo trataba de sujetarse a las viejas mitologías e imágenes de la competencia individual. ${ }^{16}$

Algunos escritores han atacado a los gobiernos de la década de los veinte por lo que llaman su política aislacionista. Consideraciones actuales sobre muchos de los tratados y pactos llevados a cabo en ese tiempo demuestran lo contrario. Joan $\mathrm{H}$. Wilson da

${ }^{13}$ Howard H. Quint y Robert H. Ferrell, eds., The Talkative President: the off the Record Press Conferences of Calvin Coolidge. Amherst, University of Massachusetts Press, 1964, p. 12.

it Kent Schofield, "The Public Image of Herbert Hoover in the 1928 Campaign", en Wilson, op. cit., p. 35.

${ }^{15}$ Ibidem, p. 44.

${ }^{16}$ Burl Noggle, "Configurations of the Twenties", en William H. Cartwright, et al., The Reinterpretation of American History and Culture, Washington, National Council for Social Studies. 1973, p. 428. 
como ejemplo la conferencia celebrada en Washington en 1924 sobre la limitación de armamento, a la que califica como el mejor intento de desarme que los Estados Unidos han llevado a cabo en este siglo. "Fue una obra importante de cooperación internacional en un periodo erróneamente llamado aislacionista." 17 Por ningún motivo queremos decir que la política de la época haya sido acertada. Sólo queremos indicar que no fue aislacionista porque los Estados Unidos se hayan negado a pertenecer a la Liga de las $\mathrm{Na}$ ciones.

Al respecto, en el ensayo "La leyenda del aislacionismo en los veinte", William Appleman Williams afirmó: "Lejos de estar aislados, las relaciones exteriores de los Estados Unidos de 1920 a 1932 estuvieron marcadas por un expreso y extenso compromiso -e intervención en los asuntos- con otras naciones."

Más recientemente, en un ensayo titulado "Las relaciones exteriores norteamericanas. 1920-1942", Robert Freeman Smith hace una crítica severa de la historiografía del consenso ${ }^{19}$ que apoyó el mito del aislacionismo de 1920 a 1940 . Celebra que las investigaciones recientes hayan puesto las relaciones exteriores de los Estados Unidos en un nuevo contexto. ${ }^{20}$ ¿Cómo puede llamarse aislacionista a un periodo en que se mandaron tropas estadunidenses a Nicaragua, Haití y Santo Domingo? Su relación con México también fue intervencionista al negarse a aceptar el artículo 27 de la Constitución mexicana, al no reconocer al gobierno de Obregón hasta agosto de 1923, presionándolo a aceptar los tratados que mantenian y preservaban privilegios para sus ciudadanos, al acusar a Plutarco Elías Calles de bolchevique y de violar la ley internacional cuando pretendió aplicar dicho artículo. El mismo presidente Coolidge dijo en 1928: "Nuestras inversiones y relaciones comerciales son de tal importancia que es casi imposible pensar en cualquier conflicto en el mundo que no nos ataña., ${ }^{21}$

Robert Freeman Smith considera que los gobiernos de esa época se creyeron o se llamaron aislacionistas porque se basaban en la ficción de una nación "única": una nación generosa, sin ambiciones, cuyas metas eran buenas para todo el mundo; veían a los paises que la desafiaban como agresores. En realidad, dice Smith, esa visión del mundo no era más que la ideología del Destino Manifiesto, presentada con una terminología moderna. Las intervenciones norteamericanas en los veinte eran consideradas desde ese punto de vista como de ayuda para conservar la paz y la prosperidad. ${ }^{22}$

Es cierto que al final de la década la administración del presidente Hoover dejó a un lado las intervenciones militares y se con-

17 Wilson, op. cit., p. xv.

18 Para una relación de la historiografía del consenso véase "Hacia una reinterpretación de la historia norteamericana...", en Secuencia. Revista americana de ciencias sociales, México, Instituto de Investigaciones Dr. José María Luis Mora, mayo-agosto, 1985, núm. 2.

19 William Appleman Williams, "The Legend of Isolationism in the 1920's", en Stanley N. Katz, New Perspectives on the American Past, Boston, Little, Brown and Company, 1959, vol. II, p. 450.

${ }_{20}$ Robert Freeman Smith, "American Foreign Relations. 1920-1942", en Wilson, op. cit., p. 65.

Williams, op: cit., p. 462.

22 Smith, op. cit., p. 65 . 
centró en una variedad de tácticas económicas, diplomáticas y culturales para reforzar la posición de los Estados Unidos en el mundo, pero de eso a haberse retirado de la política internacional hay mucho trecho. Ante el repudio público de la Liga de las $\mathrm{Na}-$ ciones, efecto de la xenofobia de esos años, el gobierno norteamericano calmó al pueblo con la promesa de apartarse de la corrupción internacional. Desde que Jorge Washington, en su discurso de despedida en 1789, pidió a sus conciudadanos que viviesen separados del mundo de la época para desarrollarse sin contaminarse, el aislacionismo fue y es el sueño utópico de los norteamericanos. No obstante, los Estados Unidos no pudieron, pueden o podrán ser aislacionistas, sencillamente porque su política exterior ha estado y está basada en consideraciones de expansión territorial primero, económica después. 